\title{
The Importance of the Sex of the Parents and of the Sex and Age of the Children with Autism Spectrum Disorders to Family Resilience
}

\author{
Paschalis Kavaliotis ${ }^{1}$ \\ ${ }^{1}$ Department of Special Education and Psychology, Faculty of Primary Education, National and Kapodistrian \\ University of Athens, Greece \\ Correspondence: Paschalis Kavaliotis, Department of Special Education and Psychology, Faculty of Primary \\ Education, National and Kapodistrian University of Athens, Greece. E-mail: apk1@otenet.gr
}

Received: February 1, 2017

Accepted: February 10, 2017

Online Published: February 15, 2017

doi:10.5539/jedp.v7n1p155

URL: http://doi.org/10.5539/jedp.v7n1p155

\begin{abstract}
The resilience of parents of children with autism is considered as one substantial strategy to address the problems in raising a child with autism spectrum disorders. In this article, the results of the investigation of the relation between the parents' family resilience and their sex, as well as their children's sex and age, are shown. The parents of 312 autistic children in Greece, all in couples, namely 624 men and women, consisted the population sample. It was considered that, at least regarding the factor of the sex, the research would result in covering some research gaps of the bibliography, such as the interest in the fathers, provided that research usually investigates the female side, ignoring, to a great extent, the paternal behavior. Moreover, it was believed that the research can practically contribute as a guide for the inclusion of the parents themselves in the therapeutic interventions of autism and highlight the importance of dividing their responsibilities in the care of the autistic child, which is usually placed on the shoulders of women, namely on the mothers, with every possible consequence on their mental, emotional and physical health. The correlation of resilience and sex also took into account the parameter of the children's sex, as well as the issue of their age, in order to draw conclusions also about the importance of these factors of impact on the parents' resilience.
\end{abstract}

Keywords: resilience, autism, autistic child, parents' sex, mother, father, child's sex, child's age

\section{Introduction}

\subsection{Parents' Sex}

The research on the importance of resilience (Note 1) in the management of the syndrome of autism usually refers to either the parents in general or the mothers in particular. The side of the father is usually addressed less by the scientific community, and it is usually examined additionally to the one of the mother or within the framework of family jointly. For mothers, in particular, much has been said, such as the following:

For Santoso et al. (2015) the balance between the risk and the protective factors against the difficult conditions in the upbringing of a child with autism affects the person's resilience. The risk factors affect the physical and mental health and especially the mothers of children with autism have to address their children's behavioral problems, a fact that significantly affects their everyday life as one of the strongest sources of causing concern. For Griffith et al. (2014) the mothers of children with autism or developmental abnormalities run an increased risk of stress and mental health problems. For Smith, Greenberg and Mailick (2014) the parents of children with autism experience high levels of stress as carers, with one of the principal stressful factors being the offensive behaviors of the children with autism. However, they wonder and investigate to what extent the mothers who take care of adolescents and adults with autism is possible to experience more incidents that cause stress during one day, in comparison with the mothers who do not raise autistic children. Yarock Rutstein (2014) sets the finding that the syndrome of autism is quite stressful for the family and it causes quite increased levels of stress, on the basis of her theoretical concern. Despite her reference to parents in general, though, the researcher had the mothers of autistic children whose children had received therapeutic intervention services, as the sample of her research. And Brown (2014), while she refers to family issues and also partially correlates her research with the interest in the parents, and she focuses on the depression which possesses the carers of children with autism in a family context, shows targeted interest in the maternal depression, therefore, this study is also classified in the 
papers that concern the mother's mental burden. Fairthorne et al. (2014) explored the effects of raising an autistic child in the mothers' quality of life, and found that the challenges the mothers of autistic children receive regarding their upbringing are much more than the ones that the mothers of normal children face, and they extend to the practical, behavioral and communication field of autism. Their quality of life is affected by the children's characteristics, such as the quick withdrawal, screaming, anger outbursts, self-injuries, violence and sleeping problems. The mothers record changes in their way of life, as their care increases, the expenses escalate, many mothers struggle to ensure services and some have suffered bullying or have been witnesses to their children's bullying. In fact, most mothers correlate the distress they feel with the sense of loss. They even reach the point of describing the feelings that the condition of the autistic child causes as the death of the child they should have. Moreover, the family relations are experienced by them as quite problematic, with their mates rejecting the autistic child, as well as the wider family often causing conditions of ignoring, or alienation, criticism and fault finding. Kwok, Leung and Wong (2014) had the marital satisfaction which the mothers of autistic children feel as the subject of their research and they highlight the great prognostic significance of the perceived stigma and the carer's burden syndrome in this field.

If the above points are indicative of the interest of research in the side of the mother, it can be added that even more is possible to be noted as well regarding the individual parameters which relate to resilience. For example, as to experiencing stress, this has been measured in higher levels in mothers, mainly those with irritable children, children of older age and children that cause self-injuries (Kotsopoulos, 2014). An explanation for the special burden that the mothers receive is given by Kwok, Leung and Wong (2014), who observe that the mothers of children with disabilities, who act as main health carers, face not only the everyday life stress, but also the one stemming from stressful factors which are unique in their children's condition. They are obliged to address special characteristics such as the offensive behavior, the reduced mental functioning, the physical limitations, the lack of self-sufficiency skills, the limited social skills. And they are in the invidious position of also addressing stigmatization, which stems from the different cultural interpretation of the disability, resulting in the increase of parenting stress. But also for the depression parameter, it is found that mainly the mothers, who are again most strongly affected, are possessed by despair and conflicted or ambivalent feelings (Bashir et al., 2014).

Much more research was accessed and the general conclusion from the review is that the interest that has existed is relatively one-sided. It is generally acknowledged that the mothers receive the greater burden within the framework of families which raise autistic children, on the one hand due to the nature of the maternal relationship between the mother and the child in general, on the other hand due to the increased obligations that the fathers face in the economic and therefore in the professional field. Bibliography usually has a lot to say for the burden the women receive, as well as the psychosomatic problems which they face due to the raising of their autistic child, both stress to cover his special needs, and depression for his condition, which seems to them, mainly not unfairly, incorrigible. The importance of the investigation of resilience for the mothers has launched a vicious, we could say, circle where they are considered to be the greater victims of the pressures of autism, without taking into consideration that this prejudice increases the pressures they receive, releasing the fathers from many more responsibilities which they should bear. Therefore, research focus on the side of women and this happens even in the cases in which the researches' titles refer to the parents and not the mothers exclusively.

We do not wish to overthrow a one so well studied finding, however, in our opinion, it is compulsory to turn the interest a little more towards the side of the resilience of the fathers and their obligations' undertaking, in a family where the obligations and the rewards should be shared equally to all. There are already findings that impose such a research addressing. It has been found, for example, that when the father suffers from depression, the stress levels for the mothers with an autistic child are significantly increased. Moreover, that the marriages of the parents with autistic children entail difficulties, dysfunctions and a great possibility to end up in a divorce; As well as that among the forms of formal and informal support, which include the husband, the friends, the early intervention in favor of the child and the medical support, the husband's support is the most common, as stated by a large percentage of women, a finding that is not surprising, since $90 \%$ of the participants in the research are married or cohabit with a mate. Even more researches that mention the wife's burden, imply or point out in one way or another the importance of the husband as supporter and enhancer of their resilience, however, they do not deal with his resilience to the extent its significance demands.

The writer has studied only one research, the one by Keller, Ramisch and Caloran (2014) which focuses exclusively on the fathers with an autistic child and examines their behavior and their feelings according to six parameters, out of which the one of paternal isolation being more direct for our research. It is the condition which fathers enter when they feel distress and loneliness due to their capacity as parents of children with autism. 
And while the mothers of these children take part in support groups, no relevant reference was made by any father in the survey, at least regarding his participation on a regular basis. Of course, paternal isolation does not work respectively for every father. Different behaviors have been recorded: firstly not all of them are in a position to announce to others their joy for very little improvements in the skills of their autistic children, or they compare their child to those who are normal and eventually feel disadvantaged, with outbursts at the expense of the marital relationship and having as a consequence the reduction of the percentages of the couple's common time. They abandon things which they used to do and while they feel isolated from their friends, at the same time it is possible that they complain that the others do not sympathize with them. One research, however, is not enough, nor does it exhaust fields, regarding the fathers, which have already been discussed a lot about the mothers. This is the second research gap which the writer traced in the international bibliography and he ensured that his investigation parameters comprise a sufficient part of his questionnaire with which the described quantitative research was elaborated.

\subsection{Child's Sex and Age}

The data from the bibliography on the sex and age of the autistic children and the burden of the resilience due to these parameters are not only occasional and indirect, but also controversial. It has already been pointed out that higher levels of stress have been measured in mothers of autistic children of older age (Kotsopoulos, 2014). Van Bourgondien, Dawkins and Marcus (2014) observe that when the children with autism enter adolescence, their mothers seem to occasionally experience an increased reduction in the effort to face the stressful factors and more anger than the mothers of toddlers. And the use of more inefficient strategies of autism management in the period of adolescence of the young person with autism, is possibly a sign of the typical stressful factors that are related to the adolescent's care, but it is possible that they also reflect an increased sense of control that the parent may have towards an older autistic young person than towards a child.

However, with regard to the correlation, for example, of parenting stress with the older age of the children, all researches do not show a consistency in findings. Almansour et al. (2013), who agree on the fact that the parents consider that their increased psychological problems are interweaved with their children's problem, do not find in the negative feelings of the parents a significant effect of the child's age, whereas Smith, Greenberg and Mailick (2014) highlighted that the behavioral problems of the autistic children remain as they get older, however, there are indications of their reduction in the course of time.

It can generally be considered that, despite the controversy and occasionality of the findings, the autistic child's age is positively interweaved with the levels of maternal stress, apparently because the fatigue and disappointment are added, weakening the defence mechanisms. Moreover, the incidents that cause stress are experienced by the mothers of children with autism more frequently than it happens with the mothers of other children.

For the relation of the resilience with the child's sex, there was no possibility to establish a theoretical framework, at least in the light of the researches in the last four-year period (2013-2016) to which the study was limited.

\section{Method}

\subsection{Purpose}

This article is part of a wider research that aimed in exploring the way in which the family resilience of parents with a child with autism spectrum disorders interacts with the social context among which the family is placed, as well as with the stress the parents experience during the upbringing of a child with autism spectrum disorders. It is important to investigate how the resilience is affected when the social support that the family receives is low and the true stress high, with variables, apart from the level of social support that the parents receive and the stress they suffer from, certain demographic characteristics of the parents and of the child, too, such as age, sex and the diagnosis of the syndrome the child suffers from. In this article, the results of the investigation of the relation between the parents' family resilience and their sex, as well as their children's sex and age, are shown. It was considered that, at least regarding the factor of the sex, the research would result in covering certain research gaps of the bibliography, such as the interest in the fathers, given the fact that research usually investigates the female side, ignoring, to a great extent, the paternal behavior. With its results, the research was considered that it could practically contribute as a guide for the inclusion of the parents themselves in the therapeutic interventions of autism and highlight the importance of dividing their responsibilities in the care of the autistic child, which is 
usually placed on the shoulders of women, namely the mothers, with every possible consequence on their mental, emotional and physical health.

\subsection{Participants}

Table 1. Demographic and other characteristics of the participants in the survey

\begin{tabular}{|c|c|c|}
\hline & n & $\%$ \\
\hline \multicolumn{3}{|l|}{$\operatorname{Sex}$} \\
\hline Men & 312 & 50,0 \\
\hline Women & 312 & 50,0 \\
\hline \multicolumn{3}{|l|}{ Nationality } \\
\hline Greek & 609 & 97,6 \\
\hline Other & 15 & 2,4 \\
\hline \multicolumn{3}{|l|}{ Religion } \\
\hline Christians & 586 & 93,9 \\
\hline Muslims & 38 & 6,1 \\
\hline \multicolumn{3}{|l|}{ Prefecture of } \\
\hline Kavala & 52 & 8,3 \\
\hline Rodopi & 80 & 12,8 \\
\hline Xanthi & 72 & 11,5 \\
\hline Cyclades & 74 & 11,9 \\
\hline Serres & 96 & 15,4 \\
\hline Drama & 120 & 19,2 \\
\hline Evros & 130 & 20,8 \\
\hline \multicolumn{3}{|l|}{ Education } \\
\hline Primary Education & 171 & 27,4 \\
\hline Secondary School Graduates & 80 & 12,8 \\
\hline Lyceum Graduates & 168 & 26,9 \\
\hline HEI /TEI Graduates & 205 & 32,9 \\
\hline Studies in Psychology or in Special Education & 0 & 0,0 \\
\hline \multicolumn{3}{|l|}{ Annual Family Income } \\
\hline Below $15.000 €$ & 266 & 42,6 \\
\hline $15.000 €-20.000 €$ & 272 & 43,6 \\
\hline Over $20.000 €$ & 86 & 13,8 \\
\hline \multicolumn{3}{|l|}{ Family Status } \\
\hline Single & 0 & 0,0 \\
\hline Married & 624 & 100,0 \\
\hline Widower/ Widow & 0 & 0,0 \\
\hline Divorced & 0 & 0,0 \\
\hline \multicolumn{3}{|l|}{ Family Relation to the Child } \\
\hline Biological Father & 312 & 50,0 \\
\hline Biological Mother & 312 & 50,0 \\
\hline Step-father & 0 & 0,0 \\
\hline Step-mother & 0 & 0,0 \\
\hline
\end{tabular}

As shown in Table 1, 624 parents of 312 children with autism spectrum disorders participated in the survey. The sample is uniformly distributed as to the parents' sex with $50.0 \%$ men and the same percentage of women. 
$97,6 \%$ of the sample, namely 609 parents, are Greeks, whereas $2,4 \%$, namely 15 participants, are of a different nationality. 586 of the participants are Christians, $93,9 \%$ of the sample, whereas the remaining $6,1 \%$, that is to say, 38 parents, are Muslims. As far as their place of residence in the Greek territory is concerned, 52 parents $(8,3 \%$ of the total number) reside in the prefecture of Kavala, 80 parents $(12 \%$ of the total number) reside in the prefecture of Rodopi, 72 participants (11,5\% of the sample) in the Xanthi prefecture, 74 parents $(11,9 \%$ of the sample) in the prefecture of Cyclades, 96 parents $(15,4 \%$ of the total number) in the prefecture of Serres, 120 parents $(19,2 \%$ of the total) in the prefecture of Drama and 130 parents $(20,8 \%$ of the sample) in the prefecture of Evros.

The total number of the respondents $(100,0 \%$ of the sample) are married and they are the biological parents of the child with autism spectrum disorders, 312 (50,0\% of the sample) are the biological mothers and $312(50,0 \%$ of the sample) the biological fathers.

The highest level of education for $27,4 \%$ of the participants (171 parents) is that of the primary education, $12,8 \%$ of the participants (80 parents) have received a low secondary education (gymnasium), 26,99\% (168 parents) have received a high secondary education (lyceum), whereas the rest of the participants, that is to say, $32,9 \%$ of the sample (205 parents) have received a post-secondary education, as they are graduates of Higher Educational Institutes (HEI) and Technological Educational Institutes (TEI).

Concerning the annual family income, $42,6 \%$ of the sample (266 parents) declared an amount below $15.000 €$, $43,6 \%$ of the total number (272 parents) between $15.000 €$ and $20.000 €$ and the remaining 13,8\% (86 parents), an income over $20.000 €$.

The children's characteristics are summarized in Tables 2-3 in this text.

Table 2. Sex of the children with autism spectrum disorders and Asperger syndrome

\begin{tabular}{lcc}
\hline & $\mathbf{n}$ & $\mathbf{\%}$ \\
\hline Sex & & \\
Boy & 253 & 81,1 \\
Girl & 59 & 18,9 \\
Diagnosis & & \\
Autism & 282 & 90,4 \\
Asperger & 30 & 9,6 \\
I don't know & 0 & 0 \\
\hline
\end{tabular}

Table 3. Characteristic age values of the children with autism spectrum disorders

\begin{tabular}{lccc}
\hline & Mean Value* & Standard Deviation & Skewness \\
\hline Kurtosis \\
\hline
\end{tabular}

With regard to the child's sex, $81,1 \%$ of the respondents, namely 506 in number, are boys' parents and the remaining 118 parents $(18,9 \%$ of the sample) are girls' parents. The average age of the 312 children whose parents participated in the research is $M-12,45$ years with standard deviation $S D=5,3$ years. $90,4 \%$ of these children, that is to say, 282 in terms of numbers, have been diagnosed with autism, whereas the remaining 30 children, $9,6 \%$ of the total number, have been diagnosed with Asperger syndrome. The children's characteristics are summarized in Tables 2 and 3 in the present text.

\subsection{Note}

The demographic characteristics of the families with dysfunctional children are factors relating directly to the parents' stress levels (Houser \& Seligman, 1991; Keller \& Honig, 2004). For this reason the questionnaire that was distributed to the participants contained specific fields the completion of which would provide the necessary demographic information on each family, namely on the sex, nationality, religion, education level, annual family income, current family status, family relation to the autistic child, the child's age and sex, as well as his accurate diagnosis. 


\subsection{Data Collection}

The supplying and collection of the questionnaires were realized by the writer from July 2015 to February 2016. The search for parents with children with autistic spectrum disorders was conducted based on the catalogues of the Center for Differential Diagnosis, Diagnosis and Support (KE.D.D.Y.) in the prefectures of the Greek territory, where an archive is kept on the children that receive a diagnosis. The parents were approached via mail sent to their residence address, to which the research questionnaire was attached, as well as an accompanying form that informed them in detail of the purpose and the aims of the research process. Special emphasis was put on the importance of confidentiality and anonymity of the information, namely that the data of the child and of the parents themselves would remain anonymous, whereas the information will be used exclusively for the needs and the purpose of the present research.

Though the accompanying form the parents were informed that they had to complete the entire questionnaire and the duration of its completion should not exceed 60 minutes. The participants were urged to contact the researcher on his mobile phone for the provision of instructions and clarifications about the correct completion of the questionnaire. Moreover, the importance of the completion by every parent separately was specifically pointed out to the participants, without there being an exchange of views among the couples, so that the achievement of the research's aims be possible.

The collection of the completed questionnaires was realized with their return to the researcher, by mail, from the families that had consented to an analysis of their answers. The return of the questionnaires to the researcher was defined to take place within 30 days after the date of their dispatching to these families.

\subsection{Data Analysis}

For the investigation of the relations that govern the Social Support, Family Resilience and Parental Stress of parents with children with Autism spectrum disorders, the following three data collection tools were used.

Social Support Index: The degree of the social support of parents who have a child with autism spectrum disorders was measured with the widely spread SSI tool (McCubbin, Patterson, \& Glynn, 1982) which assesses the family social support as a factor in family resilience (Fischer, Corcoran, \& Fischer, 2007). It contained 16 questions the answers to which were given in the 5-point Likert scale ( 0 up to 4$)$. In every questionnaire statement, the respondents can state the measure of their agreement or disagreement by choosing one of the following answers: "I strongly disagree", "I agree", "I am not sure", "I agree" and "I fully agree", which are ranked on a scale of 0 to 4 . In certain answers the scale was reversed so that a common conceptual content could be achieved. As to the answers' interpretation for the definition of the Social Support degree, the scores of the individual questions are summed, the highest scores indicating a highest Social Support degree. The span of the SSI scale was from 0 to 6 units. The SSI has a high internal validity index with a $=0,82$. The Social Support scale was used as an independent variable.

Family Resilience Assessment Scale: The FRAS scale of Tucker Sixbey (2005) was used to measure Family Resilience, based on the theoretical standard of Walsh (2006) on family resilience. It contained 66 closed-type questions which, as in the SSI case, they were answered in the Likert scale, but in a 4-point one, with values varying from 1 to 4, corresponding to the choices: "I strongly disagree", "I disagree", "I agree" and "I fully agree". The scale was reversed in four of these questions, and again for the acquisition of a common conceptual content. There was also an open-ended question. From these questions 54 were assessed, which were grouped together and formed 6 subscales of family resilience, as Tucker Sixbey (2005) suggests. More specifically, the subscales are as follows: 1) Family Communication and Problem Solving: here, 27 questions of the data collection tool correspond to it. The result of the subscale is given with Cronbach's alpha coefficient 0,96, whereas the horizontal sum of the individual questions forms the subscale's final rating with a span from 27 to 108 units. 2) Utilizing Social and Economic Resources: It is formed by 8 questions. Its rating is calculated by summing the participants' answers and it varies from 8 to 32 units. The subscale's reliability has a Cronbach's alpha index of 0,85.3) Maintaining Positive Outlook: The questions composing the subscale are 6 . The internal validity was calculated with the 0,86 Cronbach's alpha coefficient and in the same way the subscale's rating is calculated which varies from 6 to 24 units. 4) Family Connectedness: It is composed of 6 questions, among which the four ones in which the scale was reversed for conceptual reasons are also included. The sum of the score of all the questions that compose it, shapes the subscale's rating which it can also vary from 6 as minimal value to 24 as maximum value. Its reliability, measured with the Cronbach's alpha coefficient, was found to be of 0,70. 5) Family Spirituality: The subscale is composed of 4 questions. From the sum of the answers' score its rating varies from 4 to 16 units and the measurement of its internal validity gave a Cronbach's alpha coefficient 
of 0,88. 6) Ability to Make Meaning of Adversity: It is formed by 3 questions, its rating is calculated by summing the answers of the respondent parents and it varies from 8 to 32 units. The subscale's reliability has a Cronbach's alpha index of 0,74 .

Taking into consideration the exception of 12 questions, it must be noted that the rating for the measurement of the total family resilience results from the horizontal sum of the 6 subscales and may vary from 66 to 264 units. Both for the total family resilience assessment scale and its entire individual subscales, higher scores indicate higher levels of family resilience. The reliability and internal validity in total for the tool used were calculated with the Cronbach's alpha coefficient and was found to be of 0,96 . It is noted that the open-ended question was omitted.

Parenting Stress Index - Short Form: The parenting stress degree was measured by using the PSI-SF index (Abidin, 1995), which calculates the stress of the parents with children with autism spectrum disorders, which comes exclusively from their role as parents, without taking into consideration any external stressful factors, apart from the parent-child relation, as well as the child himself. The measurement tool consisted of 36 closed-type questions that were answered based on the 5-point Likert scale (1 to 5 = "I strongly disagree", "I disagree", "I am not sure", "I agree" and "I fully agree"). They were grouped together in three groups equal in number, that shaped the three index subscales as follows: 1) Parental Distress: It is made of questions 1-12 of the PSI-SF tool. The subscale rating is calculated by summing the answers and it varies from 12 to 60 units, reflecting the stress that is due to factors that concern the parents and which relate to the child's upbringing. The subscale's reliability has a Cronbach's alpha index of 0,85. 2) Parent-Child Dysfunctional Interaction: Questions 13 to 24 compose the second subscale of the Parenting Stress Index which represents the disappointment the parents feel regarding their interactions with their child. The sum of the score of all the questions that compose it, shapes its rating which may also vary from the minimum value of 12 units to the maximum value of 60 units. The subscale's reliability measured with the Cronbach's alpha coefficient was found to be of 0,68 . 3) Difficulty of Child: It is formed by the twelve last questions in the questionnaire, 25 to 36. Its rating is calculated by summing the parents' answers, it varies from 12 to 60 units and assesses their perception about the self-regulation of their child's behavior. The subscale's reliability has a Cronbach's alpha index of 0,78 .

The rating for the measurement of the total Parenting Stress results from the horizontal sum of the 3 subscales and varies from 66 to 264 units. Both for the scale and its subscales, high scores indicate high stress levels, whereas a low rating indicates low stress levels. According to the PSI-SF self-report index, the values between the $15^{\text {th }}$ and $80^{\text {th }}$ percentage point of distribution are considered to be normal stress levels, whereas for the individuals whose rating varies from values above the $90^{\text {th }}$ percentage point of distribution, it is regarded that they are in the clinical range of high stress levels. The reliability and internal validity in total for the tool used was calculated with the Cronbach's alpha coefficient and was found to be of 0,84 .

The consistency check was performed via the alpha "coefficient" of Cronbach (Cronbach's a), with the use of which the reliability of the data collection tools and their individual parts is defined. Coefficient values higher than 0,6 are considered satisfactory and they ensure their cohesion and internal validity, functioning as elements of a unified group. For the description of the quantitative variables that participated in the statistical analysis, the mean values (Mean), the standard deviations (Standard Deviation $=\mathrm{SD}$ ), the minimal and maximum values (Min-Max) as well as the third and fourth order moments (Skewness and Kurtosis) of their distributions were used. In the case of the qualitative data, their description was made via the recording of their relevant absolute (n) and percent (\%) frequencies. The linear correlation check between the quantitative variables was conducted via the Pearson $r$ correlation coefficient. The $r$ correlation coefficient varies between -1 and 1 , whereas the higher it is in absolute value, the higher the correlation between the variables becomes. Even though there are no commonly accepted limits, index values, to an absolute value, lower than 0,3 indicate weak correlations, values between 0,3 and 0,5 indicate medium correlations, whereas values higher than 0,5 mark high and strong correlations. Positive values of the coefficient suggest a positive correlation, whereas negative values, a negative correlation. The statistical significance of the correlations is checked at significance levels $\alpha=1 \%$ and $\alpha=5 \%$. For the comparison of the quantitative variables and the drawing of the survey's main conclusions, the Independent Samples t-test and the Paired Samples t-test were used depending on the nature and kind of the variables under examination. Moreover, its generalization for variables with more than two levels, the one-way Analysis of Variance (ANOVA), was used. The further study on the differences in the factors' levels is carried out with the Tukey method for multiple comparisons. The check of the hypothesis on equality of the variances on the factors' levels is performed via the Levene's test, whereas the safeguarding of the basic conditions concerning regularity and independence of the method's errors was checked via the Kolmogorov-Smirnov test 
and the Runs test, respectively. The aforementioned hypothesis checks are performed at a significance level $\alpha=b \%$. For the processing and statistical analysis of the data the IBM SPSS Statistics 20 data statistic analysis software package was used.

\section{Results}

\subsection{Parents (Sex)}

One of the main objectives of this research was the investigation of the differentiations at the levels of the measured characteristics and their subscales between the mothers and fathers of children with autism spectrum disorders. The differences of the mean values of the scales and subscales regarding the sex of the parents of the 312 children of the survey are examined with the Paired Samples t-test, the results of which are shown in Table 4 that follows. It is noted that not only are the statistically significant differentiations at significance level $a=0,05$ shown in the particular table, but also the results for all the measured scales and subscales.

Table 4. Comparison of mean values in the measurement scales and subscales regarding the respondents' sex

\begin{tabular}{|c|c|c|c|c|c|c|}
\hline Scales \& Subscales & Sex & Mean & SD & df & $\mathbf{t}$ & p-value \\
\hline \multirow{3}{*}{ SSI } & Women & 41,96 & 5,013 & \multirow{3}{*}{311} & \multirow{3}{*}{$-1,472$} & \multirow{3}{*}{0,142} \\
\hline & & & & & & \\
\hline & Men & 42,29 & 4,773 & & & \\
\hline \multirow{3}{*}{ FRAS totally } & Women & 154,37 & 8,786 & \multirow{3}{*}{311} & \multirow{3}{*}{2,721} & \multirow{3}{*}{$0,007 *$} \\
\hline & & & & & & \\
\hline & Men & 153,39 & 7,709 & & & \\
\hline \multirow{3}{*}{ FCPS } & Women & 78,86 & 4,999 & \multirow{3}{*}{311} & \multirow{3}{*}{2,056} & \multirow{3}{*}{$0,041 *$} \\
\hline & & & & & & \\
\hline & Men & 78,42 & 4,353 & & & \\
\hline \multirow{3}{*}{ USER } & Women & 22,77 & 1,637 & \multirow{3}{*}{311} & \multirow{3}{*}{1,669} & \multirow{3}{*}{0,096} \\
\hline & & & & & & \\
\hline & Men & 22,64 & 1,491 & & & \\
\hline \multirow{3}{*}{ MPO } & Women & 17,39 & 1,145 & \multirow{3}{*}{311} & \multirow{3}{*}{1,048} & \multirow{3}{*}{0,295} \\
\hline & & & & & & \\
\hline & Men & 17,32 & 1,181 & & & \\
\hline \multirow{3}{*}{$\mathrm{FC}$} & Women & 15,03 & 0,783 & \multirow{3}{*}{311} & \multirow{3}{*}{2,737} & \multirow{3}{*}{$0,007^{*}$} \\
\hline & & & & & & \\
\hline & Men & 14,88 & 0,690 & & & \\
\hline \multirow{3}{*}{ FS } & Women & 11,73 & 1,530 & \multirow{3}{*}{311} & \multirow{3}{*}{2,531} & \multirow{3}{*}{$0,012 *$} \\
\hline & & & & & & \\
\hline & Men & 11,58 & 1,455 & & & \\
\hline \multirow{3}{*}{ AMMA } & Women & 8,60 & 1,007 & & & \\
\hline & & & & 311 & 0,906 & 0,366 \\
\hline & Men & 8,54 & 0,880 & & & \\
\hline & Women & 106,83 & 10,508 & & & \\
\hline PSI-SF totally & & & & 311 & $-25,625$ & $0,000 *$ \\
\hline & Men & 124,04 & 14,454 & & & \\
\hline & Women & 35,43 & 5,233 & & & \\
\hline PD & Men & 38,59 & 5,563 & 311 & $-9,520$ & $0,000^{*}$ \\
\hline & Women & 37,56 & 3,620 & & & \\
\hline P-CDI & Men & 43,61 & 5,129 & 311 & $-20,864$ & $0,000^{*}$ \\
\hline & Women & 33,84 & 3,578 & & & \\
\hline $\mathrm{DC}$ & Men & 41.85 & 5,779 & 311 & $-28,167$ & $0,000 *$ \\
\hline
\end{tabular}

Note. ${ }^{*}=\mathrm{p}<.05$. 


$\begin{array}{ll}\text { Memo } & \\ \text { SSI: } & \text { Social Support Index } \\ \text { FRAS: } & \text { Family Resilience Assessment Scale } \\ \text { FCPS: } & \text { Family Communication and Problem Solving } \\ \text { USER: } & \text { Utilizing Social and Economic Resources } \\ \text { MPO: } & \text { Maintaining Positive Outlook } \\ \text { FC: } & \text { Family Connectedness } \\ \text { FS: } & \text { Family Spirituality } \\ \text { AMMA: } & \text { Ability to Make Meaning of Adversity } \\ \text { PSI-SF: } & \text { Parenting Stress Index - Short Form } \\ \text { PD: } & \text { Parental Distress } \\ \text { P-CDI: } & \text { Parent-Child Dysfunctional Interaction } \\ \text { DC: } & \text { Difficulty of Child }\end{array}$

According to the results of the check (Table 4), the difference of the average rating of the Family Resilience Assessment Scale as a whole emerged statistically significant, the women showing higher average rating $M=154,37$ in comparison to the men $M=153,39(t(311)=2,721, p=0,007)$. The three subscales for which similar statistically significant differentiations arose, are FCPS, FC and FS. The mothers of children with autism spectrum disorders present a higher average rating regarding Family Spirituality in comparison with the fathers $(t(311)=2,531, p=0,012)$, the respective levels of it being shaped to $M-11_{1} 73$ and $M=11,58$ respectively. Regarding FCPS, the average rating of the subscale for women amounts to $M=78,76$, higher than that of men $M=76,42\left(\tau(311)=2,05 b_{z} p=0,041\right)$, while for the $\mathrm{FC}$ component the respective values amount to $M=15,03$ and $M=14,88$ respectively, $(t(311 ;)=2,531, p=0,012)$.

Analyzing in the same way the components of the Parenting Stress index, as a whole, and its individual subscales, it is found that at significance level $a=0,05$, the male parents of children with autism spectrum disorders show higher levels of stress in comparison with the mothers. The average score of total stress for mothers is formed to $M=106,83$, whereas for male parents to $M-124,04,(t(311)=-25,625, p=0,000)$. For PD subscale the average rating for the two sexes is $M=35,4 \pi$ for women and $M=38,59$ for men, the value of the statistical function being $t(311)=-9,520$ with $p=0,000$. Regarding the P-CDI component, men show a higher average rating $M=43,61$ against women for whom the respective rating is $M=37,56$, $(t(311)=-20,864, p=0,000)$. Finally, the same differentiation $(t(311)=-28,167, p=0,000)$ is also found for the DC component, the average scores of the subscale being formed to $M=41,85$ for the fathers and $M=33,84$ for the mothers of children with autism spectrum disorders. The checks of the hypotheses for all the remaining scales and subscales did not show any statistically significant differentiations among their levels.

\subsection{CHILD (Sex)}

It was considered that it is important to seek also the differentiations that are potentially formed at the levels of the measured scales and subscales among the characteristics of the children that have been diagnosed with the syndrome of autism. Within this framework, the search for differences is conducted in the average ratings of the indexes for measuring the social support of the parents, their family resilience and the parenting stress they face, as well as all their components regarding the child's sex. The statistical Independent Samples t-test is the one used for indicating these differences.

On the basis of the check, at significance level $a=0,05$, a statistically significant differentiation emerged in the average rating of only one measured subscale of family resilience, the one of the parents' Family Spirituality (FS). The parents of girls with autism spectrum disorders show higher average levels of family spirituality $M=11,85$ against the parents of boys, for whom the average rating of the subscale amounts to $M=11,61$ $t(258,115)=-2,008, p=0,046)$. For the total and all the remaining components of family resilience, as well as for the parenting stress index and its subscales, no statistically significant differences emerged. 
Table 5. Comparison of mean values in the measurement scales and subscales regarding the sex of the children with autism spectrum disorders

\begin{tabular}{|c|c|c|c|c|c|c|}
\hline Scales \& Subscales & Child's Sex & Mean & SD & df & $\mathbf{t}$ & p-value \\
\hline \multirow{3}{*}{ SSI } & Boy & 42,14 & 4,950 & \multirow{3}{*}{622} & \multirow{3}{*}{0,187} & \multirow{3}{*}{0,852} \\
\hline & & & & & & \\
\hline & Girl & 42,05 & 4,661 & & & \\
\hline \multirow{3}{*}{ FRAS totally } & Boy & 153,92 & 8,501 & \multirow{3}{*}{622} & \multirow{3}{*}{0,230} & \multirow{3}{*}{0,818} \\
\hline & & & & & & \\
\hline & Girl & 153,72 & 7,245 & & & \\
\hline \multirow{3}{*}{ FCPS } & Boy & 78,69 & 4,790 & \multirow{3}{*}{622} & \multirow{3}{*}{0,476} & \multirow{3}{*}{0,634} \\
\hline & & & & & & \\
\hline & Girl & 78,46 & 4,242 & & & \\
\hline \multirow{3}{*}{ USER } & Boy & 22,71 & 1,638 & \multirow{3}{*}{228,418} & \multirow{3}{*}{0,266} & \multirow{3}{*}{0,790} \\
\hline & & & & & & \\
\hline & Girl & 22,68 & 1,212 & & & \\
\hline \multirow{3}{*}{ MPO } & Boy & 17,38 & 1,180 & \multirow{3}{*}{622} & \multirow{3}{*}{1,373} & \multirow{3}{*}{0,170} \\
\hline & & & & & & \\
\hline & Girl & 17,22 & 1,079 & & & \\
\hline \multirow{3}{*}{$\mathrm{FC}$} & Boy & 14,95 & 0,748 & \multirow{3}{*}{622} & \multirow{3}{*}{$-0,230$} & \multirow{3}{*}{0,818} \\
\hline & & & & & & \\
\hline & Girl & 14,97 & 0,715 & & & \\
\hline \multirow{3}{*}{ FS } & Boy & 11,61 & 1,577 & \multirow{3}{*}{258,115} & \multirow{3}{*}{$-2,008$} & \multirow{3}{*}{$0,046^{*}$} \\
\hline & & & & & & \\
\hline & Girl & 11,85 & 1,043 & & & \\
\hline & Boy & 8,58 & 0,942 & & & \\
\hline AMMA & & & & 622 & 0,251 & 0,802 \\
\hline & Girl & 8,55 & 0,966 & & & \\
\hline & Boy & 115,58 & 15,419 & & & \\
\hline PSI-SF totally & & & & 622 & 0,487 & 0,627 \\
\hline & Girl & 114,82 & 14,736 & & & \\
\hline & Boy & 37,17 & 5,683 & & & \\
\hline PD & Girl & 36,30 & 5.326 & 622 & 1,524 & 0,128 \\
\hline & & 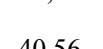 & 5420 & & & \\
\hline P-CDI & Boy & 40,56 & 5,422 & 622 & $-0,281$ & 0,778 \\
\hline & Girl & 40,71 & 5,154 & & & \\
\hline & Boy & 37,85 & 6,315 & & & \\
\hline DC & Girl & 37,81 & 6,011 & 622 & 0,063 & 0,950 \\
\hline
\end{tabular}

Note. $*=\mathrm{p}<.05$.

(Memo: same as memo in Table 4)

\subsection{CHILD (age)}

To study the impact of the age of the child diagnosed with autism on the formation of the measured scales of family resilience, social support and parenting stress and their subscales, the linear correlation coefficient Pearson $r$ was used, without the emergence of any significant results. The children's age appears to relate statistically significantly, at significance level $a=0,05$, to only two subscales of family resilience, the ones of Family Connectedness (FC) and Spirituality (FS). In both cases, the linear interactions were found to be very weak, the value of the correlation coefficient being formed to $r=-0,082$ with $p=0,04$ i and $r=0,128$ with $p=0,001$ respectively. For all the remaining components of family resilience as well as for the parenting stress 
index and its subscales, no statistically significant interactions emerged at the considered significance level (see Tables 3, 5).

\section{Discussion}

The parent's sex significantly affects the levels of total family resilience, the male parents showing lower levels in relation to women. The same conclusion is drawn for three of its components, the fathers presenting less convenience in family communication \& problem solving, lower family connectedness and lower family spirituality against the mothers with a child with autism spectrum disorders. Moreover, the differentiation of the two sexes regarding the level of stress they face is considered significant. In more than 95 out of 100 cases, the male parents form lower levels of parenting stress, parental distress and stress due to parent-child dysfunctional interaction and the difficulties the child faces. The parent's sex does not affect the social support he/she receives.

The above findings confirm the general theory which supports two views mainly regarding the sex and its connection with autism, at a level of its intake and subsequent emotional and psychological effects: a) the fathers distance themselves more than the mothers and bear lesser emotional weight in the child's upbringing in comparison with them, and b) the mothers experience bigger percentages of stress as well as depression than the fathers. More specifically, researches that do not highlight the significance of sex as the determining factor for the emotional and psychological intake of the disease, are probably exception to the general rule, such as the one by Almansour et al. (2013), who reach the conclusion that the parent's sex is not a determining factor for parental distress and concern, although they expected the mothers to be proven more affected. The rule consists of researches such as the one by Smith, Greenberg and Mailick (2014), who mention that the mothers face big consequences due to the upbringing of the autistic child, whereas, as Kotsopoulos (2014) notes, besides their increased involvement in the child's care, their high levels of stress and distress are increased when the father suffers from depression. Moreover, Kwok, Leung and Wong (2014) explain the special burden the mothers bear, who, furthermore, act as main health caregivers of their children with autism, as a result of the everyday life stress, as well as of the one stemming from, factors which are unique in their children's condition. These are the offensive behavior, the reduced mental functioning, the physical limitations, the lack of self-sufficiency skills, as well as the limited social skills. Moreover, according to Van Bourgondien, Dawkins and Marcus (2014), both the fathers and the mothers report an increased number of daily, stressful events, in particular, however, the mothers of autistic adults mention involvement in disagreements, stressful situations in the house and at work, as well as stressed caused by family members or friends more often than the mothers of children without developmental problems. Therefore, it is clear that the whole situation burdens the women far more than the men, a conclusion which the findings of our research are absolutely consistent with.

The sex of a child diagnosed with autism spectrum disorders significantly affects only his/her parents' family spirituality, the girls' parents experiencing higher family spirituality in relation to the boys' parents. The conclusion is very interesting because it concerns a potential different treatment of the autistic children by their parents according to their sex. However, the theoretical part of this paper focused on the parameter of the sex only regarding the parents and it did not include in its discussion the sex of the child with autism spectrum disorders. Therefore, it cannot be said whether the finding is consistent with the views on different or common treatment of the autistic children, a parameter that would obviously be of a great importance and significance, if it was the subject of future research work.

The age of a child diagnosed with autism spectrum disorders is related very weakly to the parents' family connectedness and family spirituality and cannot be presented as a strong conclusion of the survey. It must be pointed out that the impact of the child's age was expected to be stronger, given the view that higher levels of stress have been found in mothers with older children (Kotsopoulos, 2014), as well as more anger and less effort to address the stress causing factors (Van Bourgondien, Dawkins, \& Marcus, 2014). However, the weak relation of the age to the parents' family connectedness and family spirituality is not a non-confirmed conclusion in previous bibliography because the view that significant impact of the child's age is not found on negative feelings of the parents has also been published (Almansour et al., 2013). The conclusion of Smith, Greenberg and Mailick (2014) that the child's behavioral problems, while they are not eliminated as he/she gets older, are reduced to a certain extent, might explain things up to a point. Or even the conclusion of Van Bourgondien, Dawkins and Marcus (2014) on the stronger sense of control that the parents of children with autism have when they enter adolescence. This being said, the $8^{\text {th }}$ and $9^{\text {th }}$ conclusion of the theoretical part that the more the autistic child grows up, the more exhausted his parents get as well as lose the sense of control against the offensive manifestations of his behavior, does not seem to be strongly confirmed in our survey. The child's age may 
possibly have a greater impact, when with its increase the offensive and dysfunctional behaviors that the child has always presented are not reduced, therefore the mothers do not observe significant improvements in its problem. Namely, the child's age alone does not emerge as a strong factor of reduction of the resilience.

\section{Methodological Limitations}

The geographical distribution of the sample can be regarded as one basic limitation of the research. Despite the fact that as to its size, it is big enough and representative per district, it concerns only seven prefectures in the Greek territory. Consequently, generalizations of the conclusions that are drawn will have to be made with caution, even though it seems that they can be considered as particularly representative. An equally important limitation is that fact that the sample taken is exclusively from parents of a specific family structure. The families chosen are all two-parent families and the parents who participate in the survey have a specific family relation to the child. So, it cannot be assumed that the effects of the family structure and family relation have been adequately explored. Besides, the assessment that was made is based on the self-reports of the parents with a child with autism spectrum disorders, without other reports and information from other important persons of the parents' environment being detected, such as the rest of the families' members and health experts who possibly aid the parents. It must also be added that the survey is synchronic and interrelated, therefore it is not possible to discuss casual links between the factors under study. In addition, in this attempt no other possible parameters and co-morbidities linked to the levels of family resilience were assessed, such as depression, loneliness, the parents' interpersonal relations and social skills. All the aforementioned limitations must be taken into consideration during the study and interpretation of the present research findings.

\section{Conclusions}

As demonstrated by the survey and as it is consistent with the bibliography, the gender shows a different relation to the levels of family resilience, as the men show lower values in comparison with women. The fathers are also disadvantaged regarding family communication and problem solving, as well as the values of family connectedness and family spirituality. On the contrary, at a percentage of $95 \%$ their stress is lower than the one of the mothers, something which is also found for parental distress as well as for the stress stemming from the parent-child dysfunctional interaction and the difficulties their child has. Finally, social support does not significantly interact with the parents' sex. Regarding the child's sex, it significantly affects his/her parents' family spirituality. Namely, the parents with autistic girls experience higher family spirituality than the ones with boys, possibly because the children are treated differently, depending on their sex. Finally, the age of a child with autism appeared to relate weakly to family connectedness and family spirituality, that is to say, in this survey, it did not emerge as a strong conclusion. The impact of the child's age was expected to be stronger, according to the views expressed in the bibliography, although this correlation has been doubted in previous researches.

\section{References}

Abidin, R. R. (1995). Parenting Stress Index (3rd ed.). Odessa, FL: Psychological Assessment Resource.

Almansour, M. A., Alateeq, M. A., Alzahrami, M. K., Algeffari, M. A., \& Alhomaidan, H. T. (2013). Depression and anxiety among parents and caregivers of autistic spectral disorder children. Neurosciences, 18(1), 58-63.

Bashir, A., Bashir, U., Lone, A., \& Ahmad, Z. (2014). Challenges faced by families of autistic children. International Journal of Interdisciplinary Research and Innovations, 2(1), 64-68.

Brown, M. A. (2014). Caregiver Depression and Social Support in Families with Children with Autism. A Dissertation Presented to the Department of Special Education and Clinical Sciences and the Graduate School of the University of Oregon in partial fulfillment of the requirements for the degree of Doctor of Philosophy. Retrieved December 6, 6rom https://scholarsbank.uoregon.edu/xmlui/bitstream/handle/1794/18306/Brown_oregon_0171A_10784.pdf?se quence $=1$

Fairthorne, J., Fisher, C., Bourke, J., \& Leonard, H. (2014). Experiences Impacting the Quality of Life of Mothers of Children with Autism and Intellectual Disability. Psychology Research, 4(8), 666-684.

Fischer, J., Corcoran, K., \& Fischer, J. (2007). Measures for clinical practice and research: A sourcebook. New York: Oxford University Press. 
Griffith, G. M., Hastings, R. P., Petalas, M. A., \& Lloyd, T. J. (2014). Mothers' expressed emotion towards children with autism spectrum disorder and their siblings. Journal of Intellectual Disability Research. Retrieved December 22, 2014, from http://onlinelibrary.wiley.com/doi/10.1111/jir.12178/full

Hamilton, N. (2014). Resilience in Families with Autism Spectrum Disorder. Kaplan University. Retrieved December 23, 2014, from http://www.kaplanuniversity.edu/public-service/articles/families-and-autism.aspx

Houser, R., \& Seligman, M. (1991). A comparison of stress and coping by fathers of adolescents with mental retardation and fathers of adolescents without mental retardation. Research in Developmental Disabilities, 12, 251-260. https://doi.org/10.1016/0891-4222(91)90011-G

Keller, D., \& Honig, A. S. (2004). Maternal and Paternal Stress in Families with School-Aged Children with $\begin{array}{lllll}\text { Disabilities. American Journal of } & \text { Orthopsychiatry, }\end{array}$ https://doi.org/10.1037/0002-9432.74.3.337

Keller, T., Ramisch, J., \& Carolan, M. (2014). Relationships of Children with Autism Spectrum Disorders and their Fathers. The Qualitative Report, 19, 1-15.

Kotsopoulos, S. (2014). The parents of the child with autism. Encephalos, 51, 23-27.

Kwok, S. Y. C. L., Leung, C. L. K., \& Wong, D. F. K. (2014). Marital satisfaction of Chinese mothers of children with autism and intellectual disabilities in Hong Kong. Journal of Intellectual Disability Research, 58(12), 1156-1171. https://doi.org/10.1111/jir.12116

McCubbin, H. I., Patterson, J., \& Glynn, T. (1982). Social Support Index (SSI). In H. I. McCubbin, A. I. Thompson, \& M. A. McCubbin (Eds.), Family assessment: Resiliency, coping and adaptation-Inventories for research and practice (pp. 357-389). Madison, WI: University of Wisconsin System.

Santoso, T. B., Ohshima, N., Bontje, P., \& Ito, Y. (2015). Development of a Resilience in Daily Activities Scale (RDAS) of Mothers of Children with Autistic Spectrum Disorder. The Journal of Japan Academy of Health Sciences, 18(2), 81-95.

Smith, L. E., Greenberg, J. S., \& Mailick, M. R. (2014). The Family Context of Autism Spectrum Disorders: Influence on the Behavioral Phenotype and Quality of Life. Child and Adolescent Psychiatric Clinics of North America, 23(1), 143-155. https://doi.org/10.1016/j.chc.2013.08.006

Tucker Sixbey, M. (2005). Development of the Family Resistance Assessment Scale to Identify Family Resilience Constructs. University of Florida. Retrieved December 3, 2014, from http://etd.fcla.edu/UF/UFE0012882/sixbey_m.pdf

Yarock Rutstein, S. (2014). Raising Young Children on the Autism Spectrum: Parental Stress and Received Social Support. A Dissertation Submitted to the Faculty of the Graduate School of Applied and Professional Psychology of Rutgers, The State University of New Jersey. Retrieved November 16, 2014, from https://rucore.libraries.rutgers.edu/rutgers-lib/45156/

Van Bourgondien, M. E., Dawkins, T., \& Marcus, L. (2014). Families of Adults with Autism Spectrum Disorders. In F. R. Volkmar, B. Reichow, \& J. C. McPartland (Eds.), Adolescents and Adults with Autism Spectrum Disorders (pp. 15-40). New York: Springer. https://doi.org/10.1007/978-1-4939-0506-5_2

Walsh, F. (2006). Strengthening family resilience (2nd ed.). New York: Guilford Press.

\section{Note}

Note 1. As resilience, in this paper, is perceived an acquired and not an innate personal characteristic, which depends largely on the supportive relations of the parents, the peers and others, aiming at the strengthening of the person in order to manifest elements of positive adaptation despite the existence of serious threats, difficulties, traumas and pressures. According to Hamilton (2014) some families successfully meet the challenge of autism, while others do not manage equally well, with a significant impact on various aspects of family life. The resilience is perceived as positive adaptation within the framework of a big change and has attracted much attention in recent years because of the increased awareness of the various factors that affect it within the family. 


\section{Copyrights}

Copyright for this article is retained by the author(s), with first publication rights granted to the journal.

This is an open-access article distributed under the terms and conditions of the Creative Commons Attribution license (http://creativecommons.org/licenses/by/4.0/). 